\title{
Scaling land-surface variables for landslide detection
}

\author{
Flavius Sîrbu', Lucian Drăguț ${ }^{1 *}$ (D), Takashi Oguchi ${ }^{2}$, Yuichi Hayakawa $^{2,4}$ and Mihai Micu ${ }^{3}$
}

\begin{abstract}
As geomorphological processes operate at various spatial scales, their morphological expressions, i.e., land-surface variables (LSVs) should be scaled accordingly. Most approaches on landslide susceptibility modeling and landslide detection have been performed based on arbitrarily scaled LSVs. We propose a methodology to improve automated landslide detection by fitting each LSV to its optimal scale. We test our approach on two landslide inventories, with different landslide morphology. First, we derive seven LSVs from a DEM in a standard $3 \times 3$ moving window. Then, we rescale each LSV using focal mean statistics in increasingly larger moving windows until the optimal scale is found, i.e., scale at which logistic regression shows the best fit between the existence of landslide scarps and individual LSVs. The LSVs at the optimal scale are used as input data in a random forest (RF) model. In order to calculate the effect of scaling predictors on the accuracy of the model, we compare the results, using the area under the curve (AUC), against the results from an RF model with unscaled LSVs as input data. The results show (i) that different LSVs have different optimal scales, and (ii) the multi-scale approach improved the models significantly, from AUC $=0.73$ to 0.80 for the first study area and from $A \cup C=0.59$ to 0.73 for the second study area. Based on these results, we conclude that a multiscale approach should be considered when automated models are used in order to detect landslides, in complex terrain settings.
\end{abstract}

Keywords: Landslide scarp, Random forest, Landslide modeling, Landslide inventory, Romania, Japan

\section{Introduction}

The concept of scale stands at the basis of geomorphology and geomorphometry (Pike et al. 2008) and yet it is not straightforwardly defined in both theory and practical applications (Bishop et al. 2012; Zhilin 2008). Most often, the concept of scale has different meanings in different fields of study (Goodchild 2001). In cartography it represents the ratio between the real dimensions and the represented dimensions, while in geomorphology scale usually refers to the size of the study area (e.g., local, regional, national, or continental scale) (Broeckx et al. 2016; Gariano et al. 2017; Segoni et al. 2018). In order to have a more coherent approach, the concept of scale can be further divided into sub-concepts (Dekavalla and Argialas 2017). Relevant to our study are the observational scale, the oper-

\footnotetext{
* Correspondence: lucian.dragut@fulbrightmail.org

${ }^{1}$ Department of Geography, West University of Timisoara, Bd. V. Parvan 4, 300223 Timisoara, Romania

Full list of author information is available at the end of the article
}

ational scale, and the computational scale. These concepts can have different meanings depending on the type of data and the field of study. In geomorphometry, where the data are usually in raster format, the observational scale refers to the spatial resolution or the cell size of a digital elevation model (DEM), the operational scale describes the scale at which different process occurs and the computational scale is the scale at which the analysis is conducted, i.e., the size of the moving window used in preprocessing the predictors (Goodchild 2001).

Most often, the land surface is a product of a number of processes and control factors (Bishop et al. 2012) that have different operational scales while sharing the same physical space. When performing (space) prediction studies, the challenge is to find the most appropriate computational and observational scales of the predictor data at which they best match the process of interest, or at least the process features employed in modeling. Because the computational scale is strongly related to the observational scale, they are often discussed together or in an interchangeable manner. Furthermore, both the 
DEM resolution and the size of the moving window can influence the modeling process and the way in which the data is scaled to better fit the operational scale.

The effect of the spatial resolution of a DEM on geomorphological modeling results has been tested in different disciplines and with somewhat different results. Some studies conclude that the best option is to use the DEM with the highest available spatial resolution for modeling erosion, deposition, and rill network (Lu et al. 2017), or catchment hypsometry (Liffner et al. 2018). Other studies, however, showed that a higher DEM resolution does not necessarily produce better results (Garosi et al. 2018), and sometimes induces more uncertainty or produce worse results in applications such as connectivity index modeling (Cantreul et al. 2018), hydrological modeling (Zhang and Montgomery 1994; Li and Wong 2010;), and catchment area modeling (Becker et al. 2017).

Landslides research is an important topic in geomorphology and a significant number of studies dealt with landslide susceptibility and landslide detection. Landslide inventory maps are created traditionally by interpretation of aerial photographs and/or field mapping. In recent years, however, (semi)automated models have been utilized for producing landslide inventories (Guzzetti et al. 2012; Scaioni et al. 2014; Peppa et al. 2019), landslide susceptibility maps (Reichenbach et al. 2018), and for numerical simulation of a landslide (Iverson et al. 2015).

The methods of landslide modeling are getting increasingly sophisticated, with the use of additive statistics (Goetz et al. 2011), machine learning or artificial intelligence algorithms (Catani et al. 2013; Lagomarsino et al. 2017) and numerical modeling (Lombardo et al. 2018), and the number of studies comparing different algorithms has been increasing (Reichenbach et al. 2018). Landslide modeling, however, still depends on the input data, with various aspects, such as sampling strategy, size or scale (Arnone et al. 2016; Reichenbach et al. 2018; Schlögel et al. 2018).

Spatial resolution of a DEM is important in modeling landslide susceptibility (Sulaiman et al. 2017; Wang et al. 2017; Schlögel et al. 2018), and it should be adapted to the size of the study area (Reichenbach et al. 2018) or the average size of the landslides (Claessens et al. 2005). Other studies showed that scaling the predictors can improve the overall accuracy of the model. A straightforward upscaling method is resampling a DEM to lower resolutions, and then deriving the predictors and testing the scale (spatial resolution) that produces the best model (Catani et al. 2013). This methodology has shown that not all predictors perform best at the same scale, thus, Paudel et al. (2016) introduced an approach to find the best scale for each predictor and used it in the model for landslide susceptibility prediction. These findings were further supported by Pawluszek et al. (2018) who used scaled predictors for automated landslide detection.
Choosing the appropriate input data in terms of DEM resolution (observational scale) and the appropriate computational scale to derive different predictors (operational scales) are still challenges in landslide detection. We propose a methodology that solves the problem of adapting the best operational scale in landslide detection by iteratively rescaling each predictor and finding its best fit. We illustrate this by modeling two different landslide scarp inventories without preprocessing to evaluate the success of the proposed approach. The new approach has been developed as an algorithm for the open source $\mathrm{R}$ platform (R_Core_Team 2017) and can be freely downloaded to use or improve.

All the models that we build and present in this paper are used for automated landslide detection rather than landslide susceptibility modeling.

\section{Methods/Experimental}

\section{Study areas and landslide inventory characteristics}

In order to test if our hypothesis works on different settings, we have chosen two distinct study areas that are different in geology and land cover and thus they produce landslides with different morphogenetic typology. By using the two areas, we decrease the possibility that our results are site specific and thus increase the confidence in generalization of our conclusion. The modeling results, for the two areas, are not directly compared against each other, but are utilized to compare for the scaled models against the unscaled models. For both areas, compilation of the landslide inventory precedes the acquisition of the DEMs, so that the landslide scarps should be recognizable in the DEMs.

The first study area is located in the Shizuoka Prefecture, in the southeast of Honshu Island, Japan (Fig. 1) and covers an area of about $125 \mathrm{~km}^{2}$. Hillslopes in this area are mostly covered by forest. Lithology is dominated by a melange matrix of the Late Eocene to Early Miocene accretionary complex with chaotic facies with intrusions of limestone and marble blocks of the same accretionary complex. Along the river valley, in the eastern study area, Late Pleistocene to Holocene fan deposits can be found. The available data consist of a DEM based on airborne LiDAR (light detection and ranging) at a $5 \mathrm{~m}$ spatial resolution, and an inventory of 371 landslide scarps (Uchiyama et al. 2012). The inventory was provided by the National Research Institute for Earth Science and Disaster Resilience, Japan (NIED) (Shimizu et al. 2002; Oyagi et al. 2015). The inventory was derived by visual interpretation of topographic discontinuities using stereo-paired aerial photographs at a 1:40,000 scale, acquired in the 1970s. It includes historical landslides that have occurred in the past decades to centuries, wider than $150 \mathrm{~m}$, but does not include smaller shallow slope failures. The majority of landslides are shallow slides occurring on moderate to steep slopes but deep-seated 


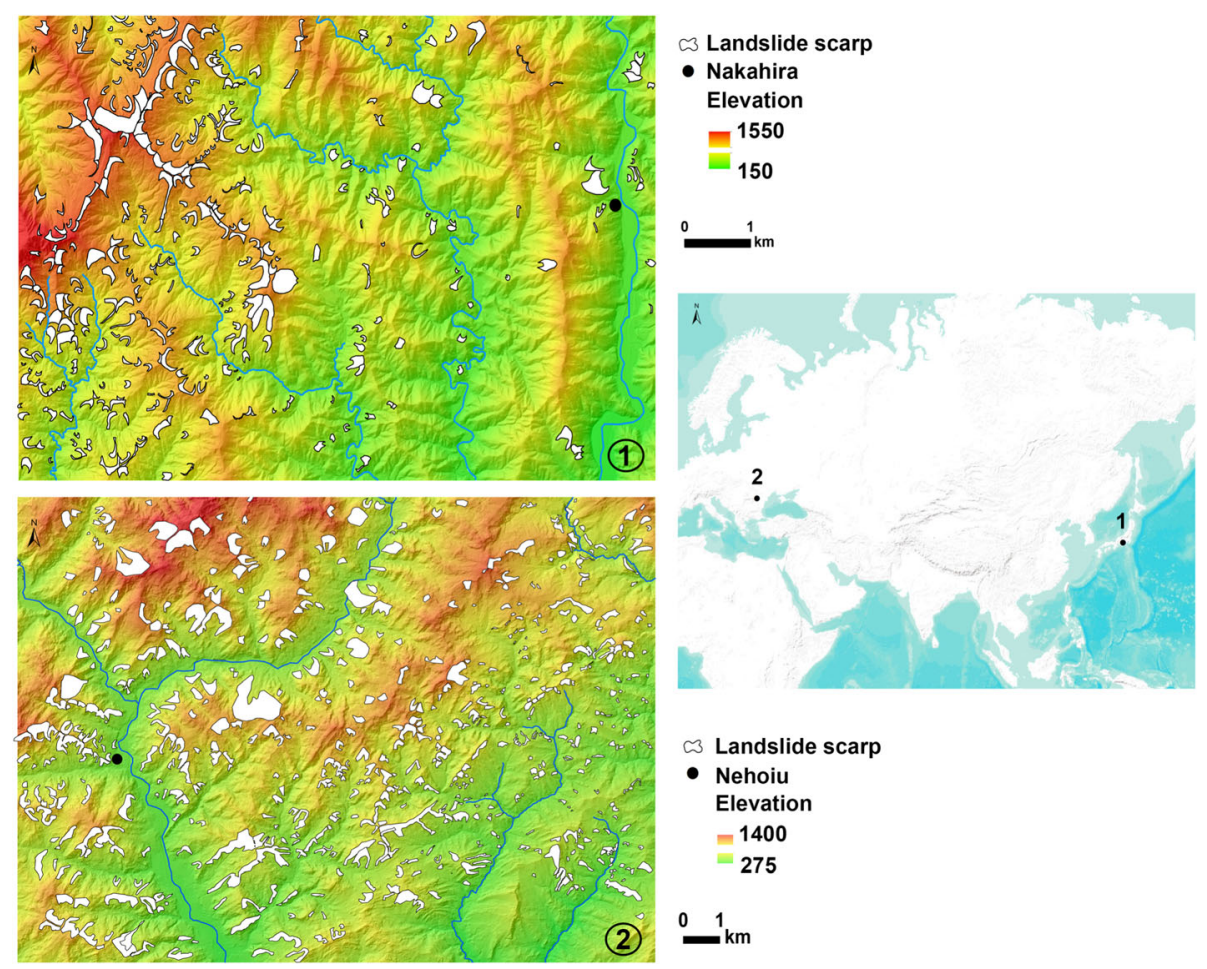

Fig. 1 Landslide scarps inventories in Shizuoka, Japan (1) and Buzău, Romania (2), and their locations (right)

landslides are also contained in the inventory. The use of historical landslide inventories is advantageous for the landslide modeling in that it summarizes past multiple landslide events reflecting distinct topographic features in a DEM and various environmental conditions (Fig. 2).

The second study area is situated in the Buzău County (Fig. 1), Romania, and covers about $800 \mathrm{~km}^{2}$ at the contact between the Romanian Curvature Carpathian Mountains and the Subcarpathian Hills, which are part of the Vrancea seismic region. Cretaceous and Palaeogene flysch (i.e., alternations of thick cohesive sandstone with schistose intercalations of marls, clays or bitumen) is specific to the mountainous section, while hills and depressions are built on less cohesive Neogene molasses deposits, i.e., a heterogeneous mixture of clays, marls, salt breccias, loose conglomerates, sands, and loess-like deposits. The morphology of landslides reflects the litho-structural conditioning. Large, dormant (partially relict), landslides prevail in the mountainous flysch sector featuring numerous reactivations in the form of shallow translational slides across the broad terminal accumulation of landslide deposits, mainly due to the active river undercut (Fig. 2). The molasses sector features very frequent but low-magnitude landslides and is characterized by the widespread presence of shallow translational earth slides and earth flows, reflecting at least three propitious triggering frameworks: spring showers and snowmelt, torrential convective summer showers and less heavy but long-lasting autumn rains. This leads to numerous sequences of first-time failures and subsequent reactivations which are responsible for the development of large landslide complexes, typically 5 to 10 ha, with a polycyclic evolution (Fig. 2).

Less than $10 \%$ of the inventory could be considered multi-temporal, since it covers the period of the last 40 years. The majority of the inventory is being represented by shallow and medium-seated earth and debris slides in the south-eastern half, which corresponds to the molasses formations of the Subcarpathian Hills; while for the Carpathians, it gathers both depletion and accumulation sectors of shallow to deep-seated landslides. It was compiled from different sources. Some of them have been reconstructed from archive data (Institute of Geography, Romanian Academy), while others resulted from detailed geomorphological field mapping and databases of the local authority: Buzau County Inspectorate for Emergency Situations (Zumpano 2014; Zumpano et al. 2014). The largest proportion $(>90 \%)$ of data is represented by a single-period inventory obtained in 2014 through digital stereographic photo interpretation using color aerial ortho-photographs (cell size $2 \mathrm{~m}$, resampled from an original $0.5 \mathrm{~m}$ ) taken in 2005 by ANCPI (Agentia Nationala de Cadastru si Publicitate Imobiliara) Bucharest. The anaglyph 3D visualization was created using the "stereopair from DTM" (DTMdigital terrain model) module of ILWIS Version 3.4 software. The $10 \mathrm{~m}$ resolution DEM used for the landslide 

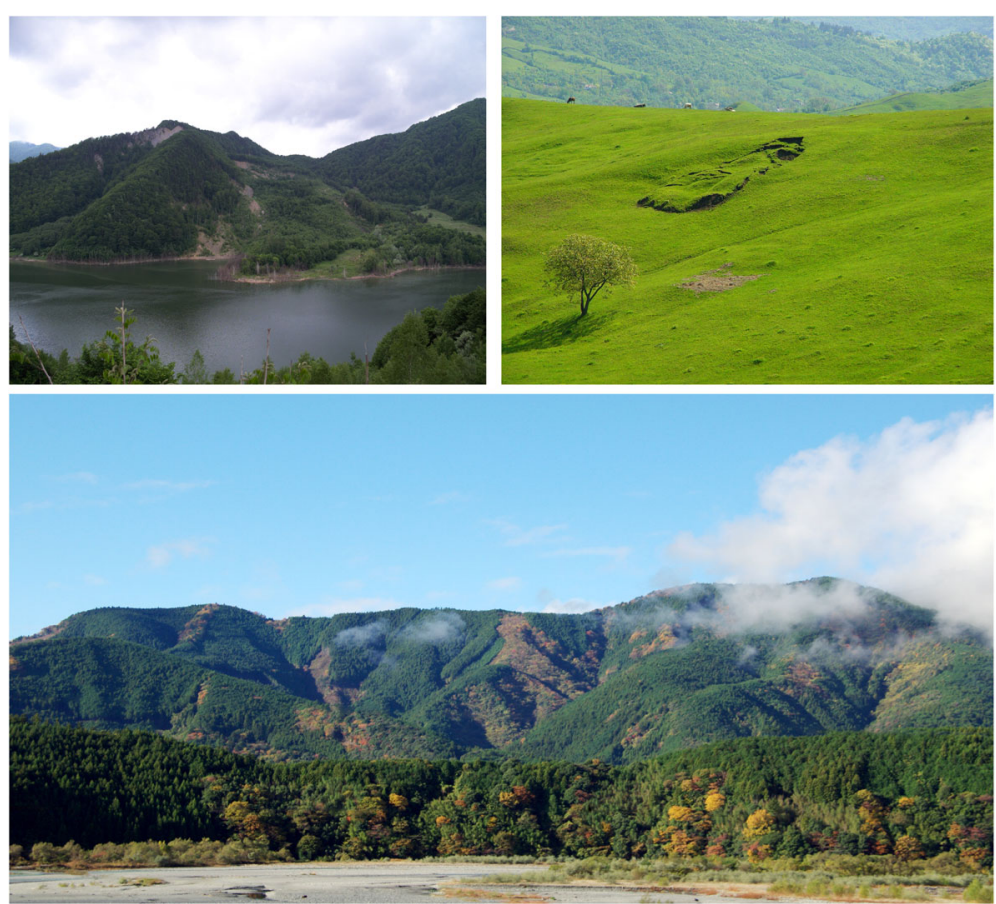

Fig. 2 High magnitude deep-seated landslides in the Buzău Carpathians, upper left; low magnitude, clearly individualized shallow earth slide in the Buzău Subcarpathians, upper right; mountain slopes with historical landslides, that are mostly covered by vegetation in Shizuoka Prefecture, lower image

interpretation was obtained from linear interpolation of topographic contour lines (20 and $5 \mathrm{~m}$ interval) derived from 1:25,000 topographic maps published by the military topographic direction (Damen et al. 2014). The DEM used for model construction is an optically derived DTM with a spatial resolution of $4 \mathrm{~m}$.

The landslide scarps from the two study areas show significant differences in size (Fig. 3). The average size of the landslide scarp in the Buzau County study area is 8.64 ha and the median size is $4.28 \mathrm{ha}$, while the mean size of the landslide scarps in the Shizuoka Prefecture study area is 2.35 ha and the median value is 1.44 ha.

The landslides analyzed in the present study are not differentiated based on their origin or morphologic traits. Thus, the term landslide in this paper includes shallow or deep-seated slides, flows, and avalanches.

\section{Land-surface variables}

We have chosen only predictors that can be extracted from a DEM and ignored predictors like land cover and lithology, which are known to hold an important influence on landslides but fall outside the scope of the study. Furthermore, these land-surface variables (LSVs) had to satisfy two additional conditions: they can be extracted using moving windows of variable size, and their influence on landslide scarps has a clear geomorphological explanation. Thus,

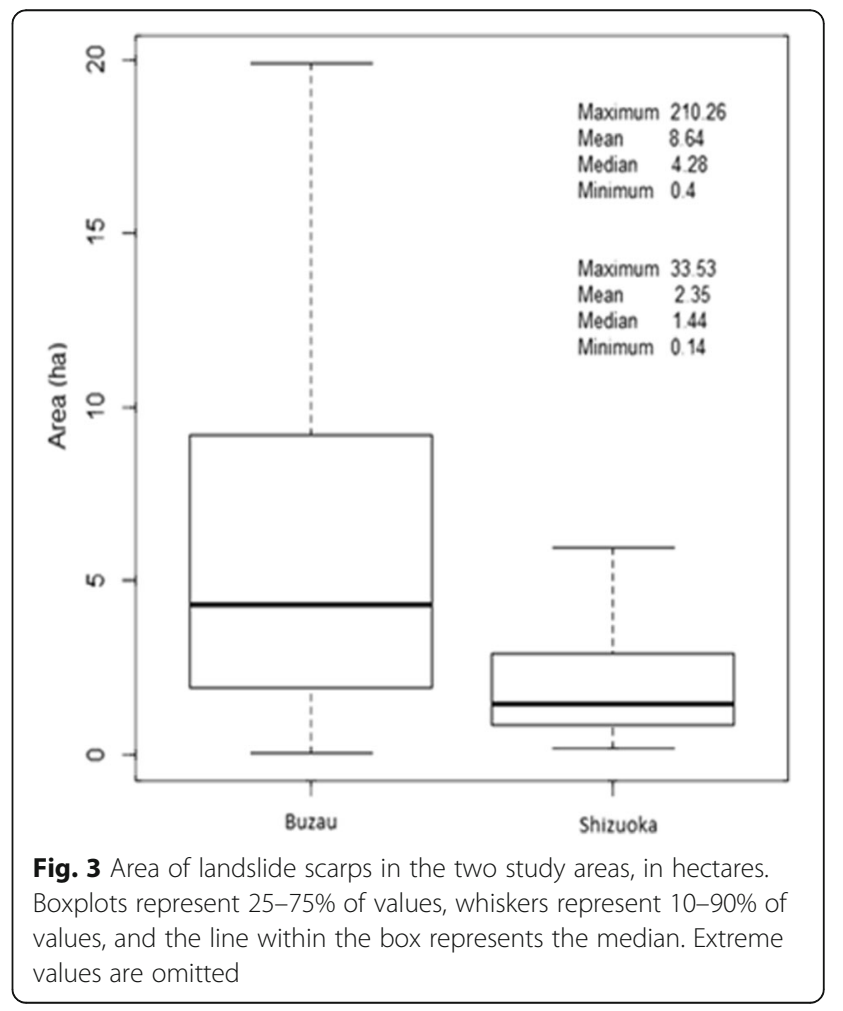


LSVs like total catchment area or hillshade were not considered.

The LSVs were derived, in a standard $3 \times 3$ moving window, from the available DEMs using the RSAGA package (Brenning 2008) that implements the algorithms of SAGA (System for Automated Geoscientific Analyses; Conrad et al. 2015) into the R software as follows:

- Elevation, as expressed by DEM values, is regularly used as a predictor in modeling of landslides (Catani et al. 2013; Reichenbach et al. 2018)

- Mean curvature is a second derivative of the elevation and was computed according to the methodology proposed by Moore et al. (1991)

- Plan curvature is calculated perpendicular to the direction of flow and is generally used to describe the divergence or convergence of flow (Catani et al. 2013)

- Profile curvature is calculated on the direction of flow and is generally used to characterize erosion/ deposition potential of a slope (Catani et al. 2013)

- Slope gradient is the most widely used predictor in landslide modeling (Reichenbach et al. 2018)

- The topographic positioning index (TPI) gives an estimate of the slope position of landslides and was found to have a scale dependency (Wang et al. 2018)

- The topographic roughness index (TRI) measures the unevenness of a terrain by calculating the difference in elevation between a cell and the average of the surrounding cells, in a given window size (Olaya 2004)

- Terrain surface texture (texture), emphasizing fine differences in elevation of different pixels, was derived with the method proposed by Iwahashi and Pike (2007).

The values of these LSVs were associated with one randomly sampled point per scarp, as well as an equivalent number of randomly sampled non-scarp points (Santacana et al. 2003). It is possible for the non-scarp points to be located on landslide bodies.

\section{Scaling of LSVs}

For scaling of LSVs, we propose a methodology that can (i) analyze the degree of fitting between each predictor and the presence/absence of landslide scarps, (ii) adapt to different study areas or scenarios, and (iii) easily integrate into a (semi)automated modeling approach (Fig. 4).

At first, each LSV was re-scaled to successively broader representations of topography with focal mean statistics in increasing squared windows, starting from $3 \times 3$ cells (Dragut et al. 2009), using the RSAGA package (Brenning 2008).

For each LSV, the best scale was evaluated in an iterative process, by fitting a simple binary logistic regression
(Brenning 2005; Deluigi et al. 2017; Cauzzi et al. 2018;), where each scale of the LSV is, in turn, the predictor variable and the scarp presence/absence is the predicted variable. The process continues as long as the result of the logistic regression improves, and it stops when the scale that best describes the presence/absence of scarps is found. All the available points for presence/absence of landslide scarps are used for the logistic regression.

The performance of each model was evaluated using the AUC (area under the curve) metric. The AUC is obtained by plotting all possible sensitivity (true positive) rates against 1 -sensitivity (false positive) rates, and returns values between 0.5 (no discrimination between presence/absence) and 1 (perfect discrimination) (Hosmer and Lemeshow 2000). The AUC values are computed using the ROCR package (Sing et al. 2005). Because the aim of the test is to evaluate the goodness of fit, the data used for model evaluation was the same as the training data.

\section{Prediction of landslide scarps}

In order to assess the impact of scaling the predictors in modeling, two models were produced and compared: one that used the scaled predictors as input data, while the other used the default LSVs (derived in a $3 \times 3$ moving window, without further smoothing). The latter was considered the baseline in evaluating the scaling performance. Because the aim is to test the prediction power of the model, the input data has been split into $70 \%$ and $30 \%$, for training and validation respectively.

The employed modeling technique is random forest (RF; Breiman 2001). RF is a robust, easy to use, and computationally efficient classification algorithm (Chen et al. 2018) with a high level of accuracy (Youssef et al. 2016; Chen et al. 2017; Behnia and Blais-Stevens 2018). It produces a number of classifications, based on a binary decision algorithm, called decision trees and uses all of them, with a majority voting, to form the best prediction model. Thus, each classification is assigned to a certain class (presence or absence) if the majority of decision trees do so. Furthermore, it is possible to obtain the results as probabilities of class assignment for a certain sample by evaluating the strength of the majority of decision trees. RF has several characteristics linked with the input data that are useful for our purposes: (i) there is no need for the input data to have a specific frequency distribution, (ii) it is not sensitive to outliers in the input data, (iii) it can use a great number of predictor variables, and (iv) it is not sensitive to collinearity in the predictor variables (Catani et al. 2013).

The modeling was performed using the package "randomForest" (Liaw and Wiener 2002) in the R software, with the settings $n$ tree (number of classification trees) $=$ 501 and $m$ try (number of candidate variables) $=3$. The 


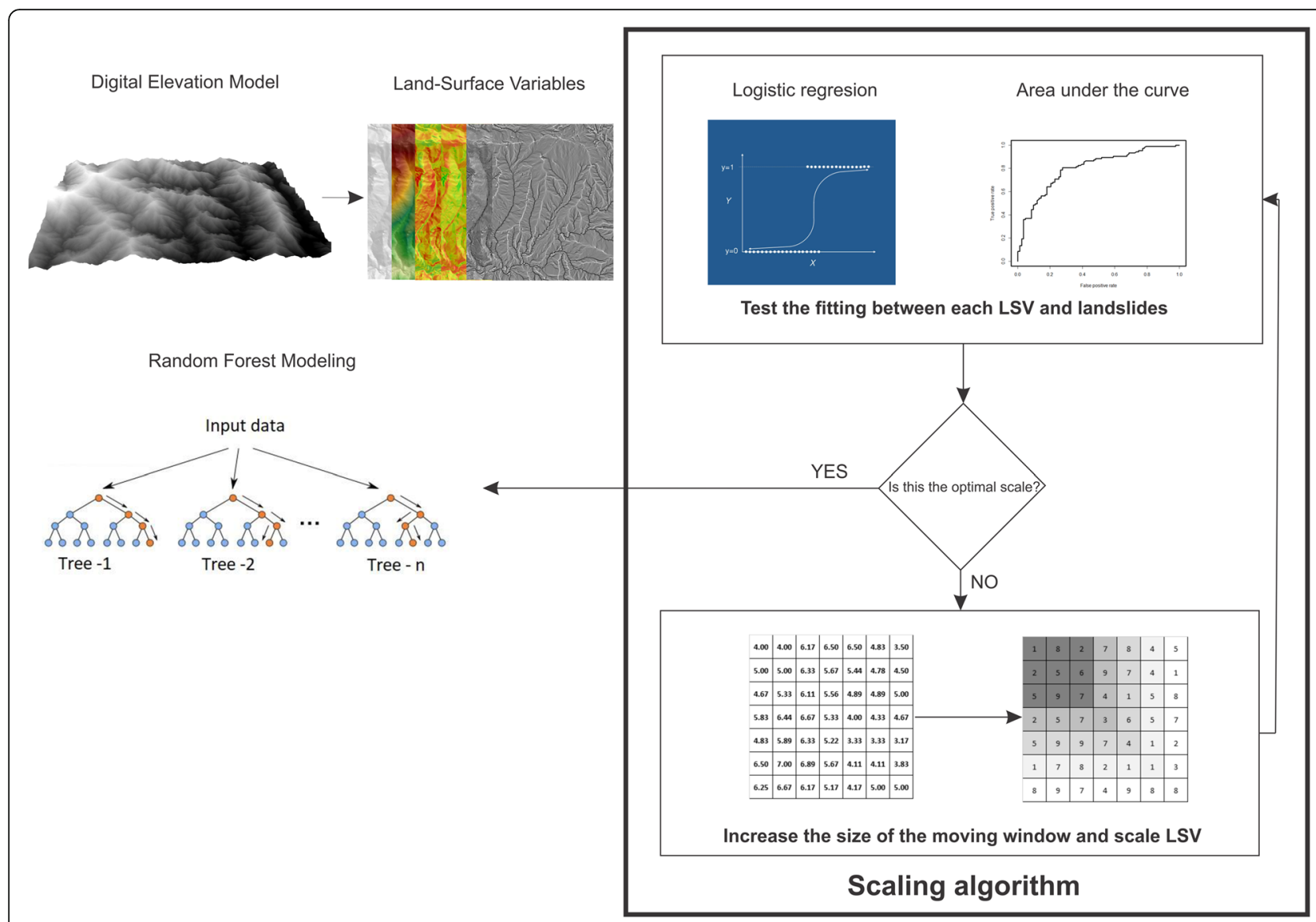

Fig. 4 Experimental work flow

ntree value was set in a "trial and error" method in which the model was run with a high number of trees and the results were plotted against the OOB (out of bag error). The ntree value at which the curve flattened was selected as the appropriate one for modeling because a further increase in ntree would not improve the model (Catani et al. 2013). The mtry value was obtained by the standard formula, $\sqrt{p}$, where $p$ is the number of variables.

Another output of an RF model is the ranking of predictor importance in creating the model, the so-called variable importance $(V I)$. There are many ways for computing this but we used the simplest method, based on the decrease in mean accuracy. The OOB is calculated using all the predictors and then, in turn, omitting one predictor. The differences between the two OOB values are averaged for all the decision trees and are normalized using the standard deviation of the differences. The predictors that are found to reduce the $\mathrm{OOB}$ when used, are regarded as the most important (Liaw and Wiener 2002).

In order to account for the random part in RF, the models were run for 25 times and the results were averaged and evaluated using the validation data set and $A U C$.

\section{Automatic procedure}

Catani et al. (2013) and Paudel et al. (2016) show that scaling of all or individual predictors can improve the model of landslide susceptibility, and Reichenbach et al. (2018) and Schlögel et al. (2018) show that choosing the appropriate DEM resolution is important and can influence the overall accuracy of the model. However, preprocessing of input data (predictors) in regard to scale is still not a common practice in landslide modeling. Moreover, our literature review on landslide modeling indicates that there are more studies for choosing the right method than studies for calibration of input data to the model.

For easier preprocessing of the predictors in order to fit them to the most appropriate scale of analysis, we provided a script that can run with the free software R, available in Additional file 1. The necessary input data for the script is a DEM from which the predictors will be extracted, and a shapefile containing landslide presence/absence data for the variable that is to be modeled. Note that for this study, we have chosen to work with only eight predictors, but the script can extract more predictors from an input DEM. 


\section{Results and discussion}

\section{Scaling of predictors}

LSVs calibrated to scale could better predict the scarp presence/absence in five out of eight cases for the Shizuoka study area, and in six out of eight cases for the Buzau study area (Fig. 5). Elevation and profile curvature display the best prediction of the landslide scarps at their default scale in both areas, and plan curvature also shows the best prediction at the default scale for Shizuoka, but at a $17 \times$ 17 pixels for Buzau. Three predictors (elevation, profile curvature, and mean curvature) were found to perform best at the same scale in both study areas (Fig. 5).

The performance of the predictors for both study areas shows that two predictors (plan curvature and texture) display a higher scale for Buzau, while three others (slope, TRI, and TPI) show a higher scale for Shizuoka. Pawluszek et al. (2018) also found that TPI performs better when it is scaled using a relatively larger moving window. These results suggest that the relationship between the size of landslides and the scale of predictors is not straightforward. If such a relationship exists, then it is most probably defined for each individual predictor, and is more complex than a simple linear one. This confirms the findings of Paudel et al. (2016) and Pawluszek et al. (2018) in that there is no universal scale that works for all LSVs, but each LSV performs best at its own scale.

The curvatures, with one exception, perform better at fine scales, while slope, texture, TPI, and TRI perform better at broad scales. When scaled, the prediction power of individual LSVs increases in both study areas. The most significant increase in the Shizuoka study area is for slope $(\triangle \mathrm{AUC}=0.10)$ and TRI $(\triangle \mathrm{AUC}=0.11)$. For the Buzau study area, the biggest increase is for mean curvature $(\triangle \mathrm{AUC}=0.07)$. The increase in AUC for a scaled LSV compared to the default is greater for the Shizuoka study area, with the exception of elevation, plan, and profile curvatures (Fig. 6).

\section{Prediction of landslide scarps}

The results show a significant improvement in the accuracy of the models for both study areas when the predictors have been scaled. The increase is particularly significant in Buzau, where AUC changed from 0.59 to 0.73, corresponding to a poor to a good model. For Shizuoka, the increase in accuracy is more limited, from $\mathrm{AUC}=0.73$ to 0.80 , but is still important, especially considering that the model with default predictors had already shown a good accuracy (Fig. 7).

Building a model for detecting landslide scarps gets increasingly more complex as the terrain is more variable and the landslides are of different type. The relation between landslide scarps and LSVs is not linear and generally not intuitive. For example, there is no clear relation between the slope of a scarp and the slope of the terrain before the landslide occurred. A deep-seated slide can occur on a gentle slope but the slope of its scarp can be steep. And also an older, deep-seated slide can occur on a much steeper slope but the scarp can be eroded and thus less steep.

\section{Variable importance}

Our study found out that not all the LSVs have their best fit at the same scale. This controls the final accuracy of the model, because using each LSV at its appropriate scale not only improves the modeling accuracy (Paudel et al. 2016) but also strongly affects the ranking of predictor importance (Pawluszek et al. 2018). Indeed, for the Buzau study area, the ranking changes significantly when the model is constructed with scaled predictors (Fig. 8). For the default model, elevation stands as the most important predictor, followed by a group of other three predictors with similar importance (TRI, TPI, and slope). Curvatures have lower importance while texture has a negative importance coefficient, which indicates a negligible contribution to the model. For the scaled model, two predictors stand out as important, slope, and

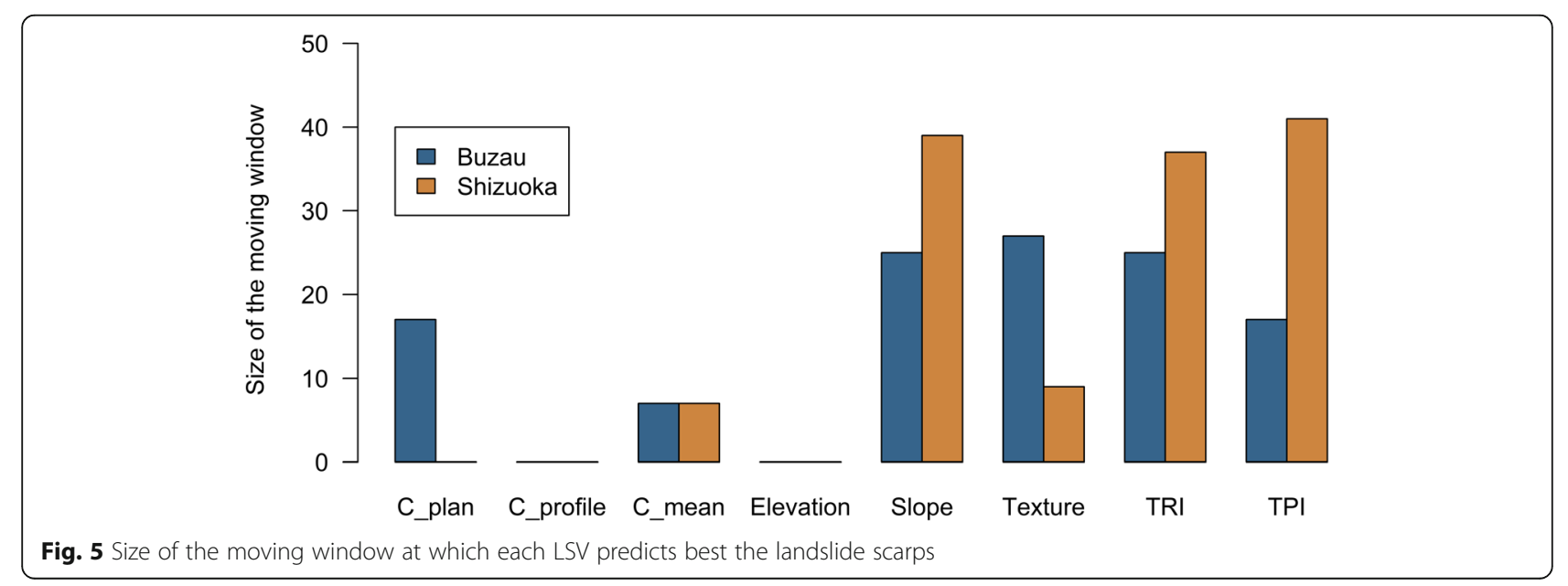




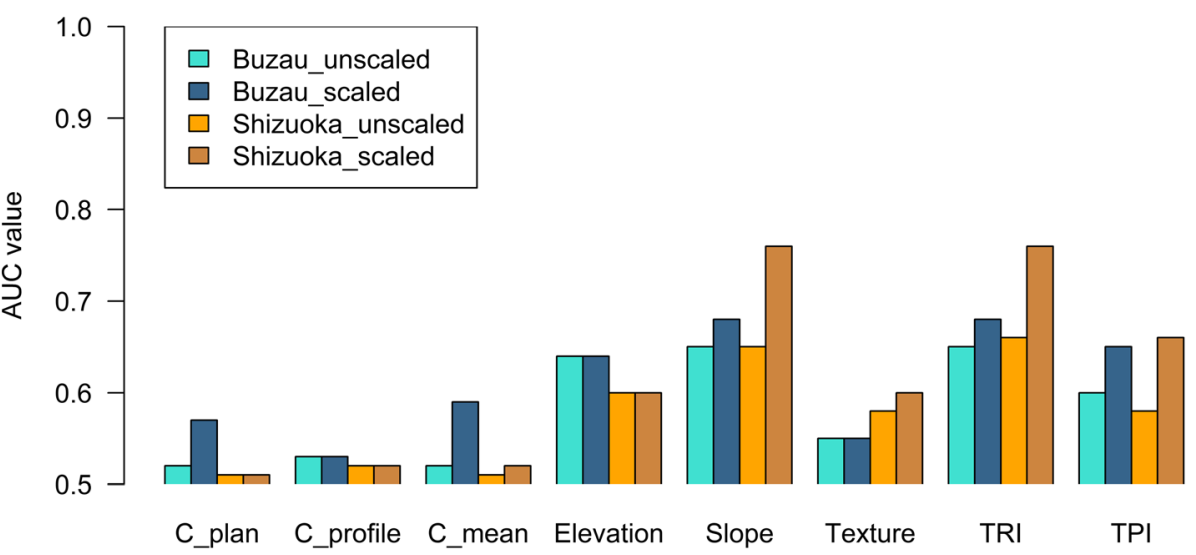

Fig. 6 AUC results for landslide scarps modeling with individual predictors

TPI, and the variable importance graph shows all the predictors influence the model, even texture. For the Shizuoka study area, the default model's predictor ranking is quite similar to that of the Buzau default model, elevation stands as the most important predictor, followed by TRI, slope, and TPI, while curvatures and texture are the list important. For the scaled model, there is an even bigger gap between elevation and the other predictors. Notable is the rise in importance of the texture when scaled, which becomes the second most important predictor (Fig. 8).

These findings are supported by similar results presented by Paudel et al. (2016) and Pawluszek et al. (2018). Also, by testing the effect of DEM resolution on the accuracy of landslide models, Catani et al. (2013) found that using a DEM with a different spatial resolution changes the ranking of variable importance. This is in strong contrast with the vast majority of studies on landslide modeling that use all the LSVs at the same scale. The problem of model accuracy can be, partially, solved by using an algorithm that can have a high number of predictor variables from which those that improve the model are chosen (e.g., RF). However, the possibility that some LSVs can be ranked of little or no importance to the model occurs, because they are not used at the proper scale, affecting the geomorphological interpretation of the model.

It is important to note that there are great differences in the ranking of variable importance between results from RF (Fig. 8) and those from the logistic regression (Fig. 6). The fact that different modeling approaches produce different variable importance rankings, for the same input data, has also been reported in previous

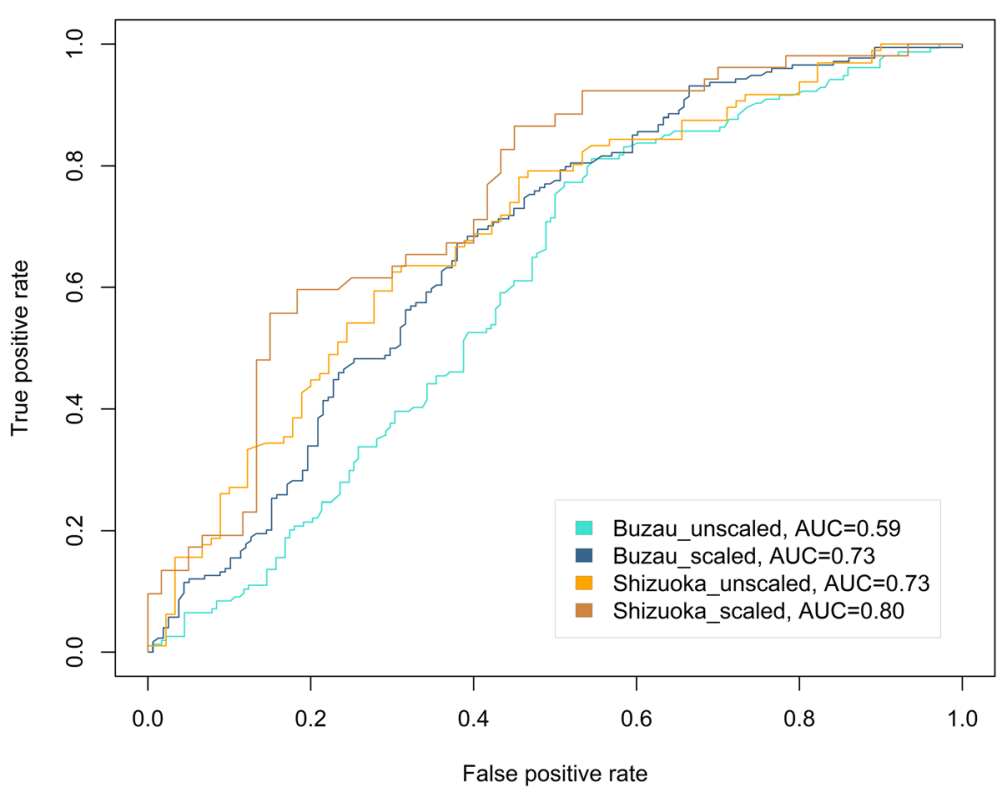

Fig. 7 Model accuracy, measured using AUC 


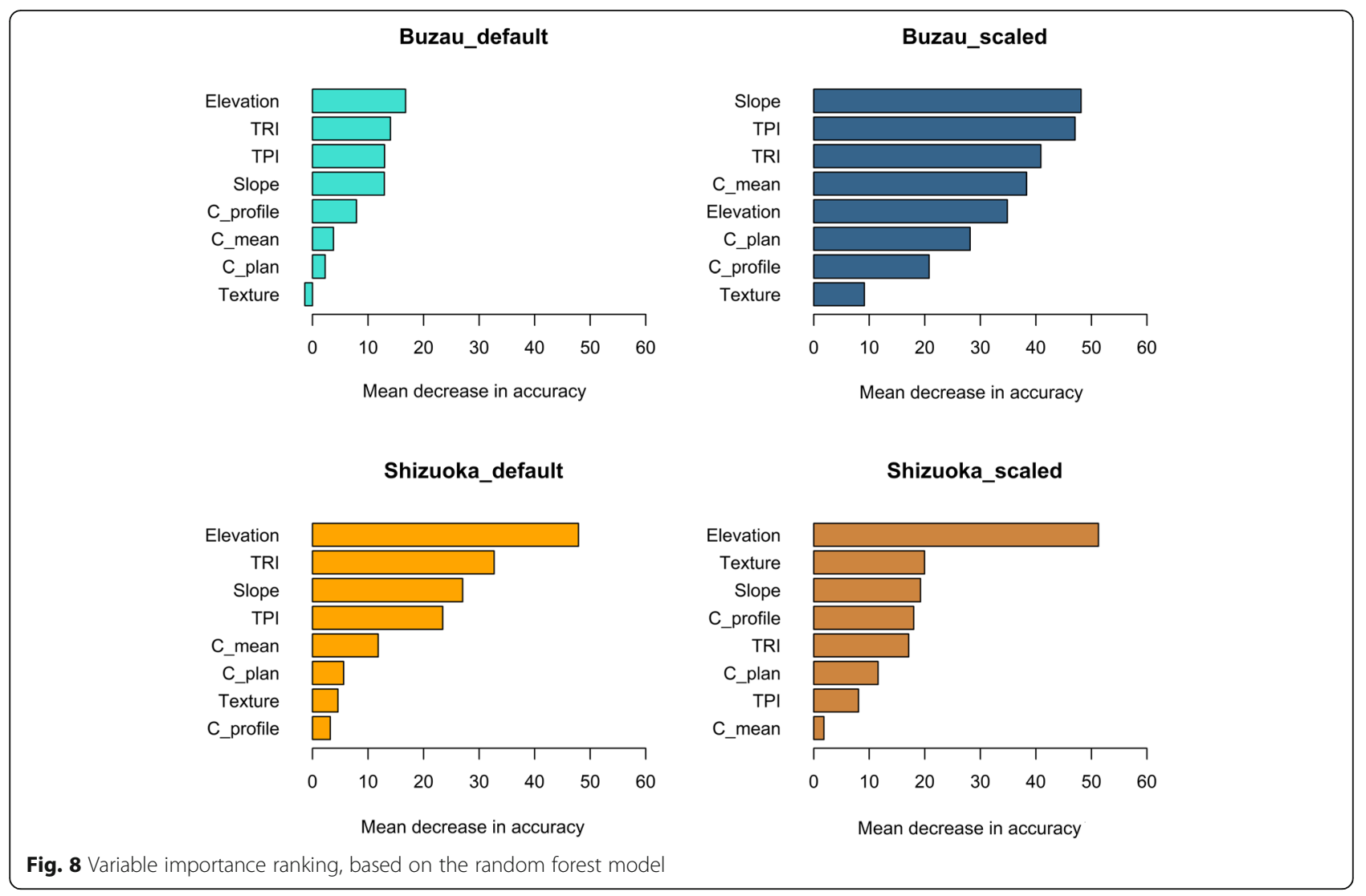

studies (Goetz et al. 2015; Chen et al. 2017), and the reason for this is beyond the scope of this paper. The main point in our approach is to compare the scaled variable against the unscaled variable for a better fit based on a simple regression, since more complex modeling techniques, like RF, work best when they use multiple predictors (Catani et al. 2013).

\section{Scaling factor and landslide size}

Our results show that, with the exception of profile curvature, all others LSVs have a better fit to the landslide scarps when they were scaled, and that there is no universal scale at which the LSVs should be used, each individual LSV has a particular scale for a particular study area. When we transform the scaling factor, from pixels to hectares, in order to compare the results with the average size of the landslides, we find that there are significant differences between predictors and between the two study areas (Fig. 9). For the Shizuoka study area, five LSVs (plan curvature, profile curvature, mean curvature, texture, elevation) that are not scaled or scaled to represent an area less than 0.25 ha $(50 \times 50 \mathrm{~m})$ and only three variables are scaled broadly. In the Buzau study area, by contrast, three LSVs (profile curvature, mean curvature, elevation) are scaled to finer sizes and five are scaled broadly.
It has long been acknowledged that the multitudes of processes, at different spatial and temporal scales, occupy the same physical space (Schmidt and Andrew 2005) and that DEMs with different pixel sizes portray different processes and landforms for the same area (Claessens et al. 2005). This is important in all geomorphological modeling and is particularly important in models to detect past landslides, because the vast majority of landslides are relatively big, and on both their scarp and body other processes, at smaller scales, can take place and develop a local microtopography (e.g., rill networks and gullies). All the LSVs that are scaled to finer areas seem to improve the modeling accuracy due to a better representation of topography through elimination of local noise in the form of microtopography (Fig. 10). Furthermore, the area that they are scaled to seems to fit the range of spatial resolutions at which other studies have found to be most appropriate to model landslides. Thus, when studying the effects of DEM resolution on landslide modeling in the past, DEMs with spatial resolutions ranging from 2 to $500 \mathrm{~m}$ were investigated and the conclusion was that the best results were obtained using DEMs with a spatial resolution of $10 \mathrm{~m}$ (Arnone et al. 2016; Wang et al. 2017; Schlögel et al. 2018;), $20 \mathrm{~m}$ (Sulaiman et al. 2017; Pawluszek et al. 2018) and even $50 \mathrm{~m}$ (Catani et al. 2013). 


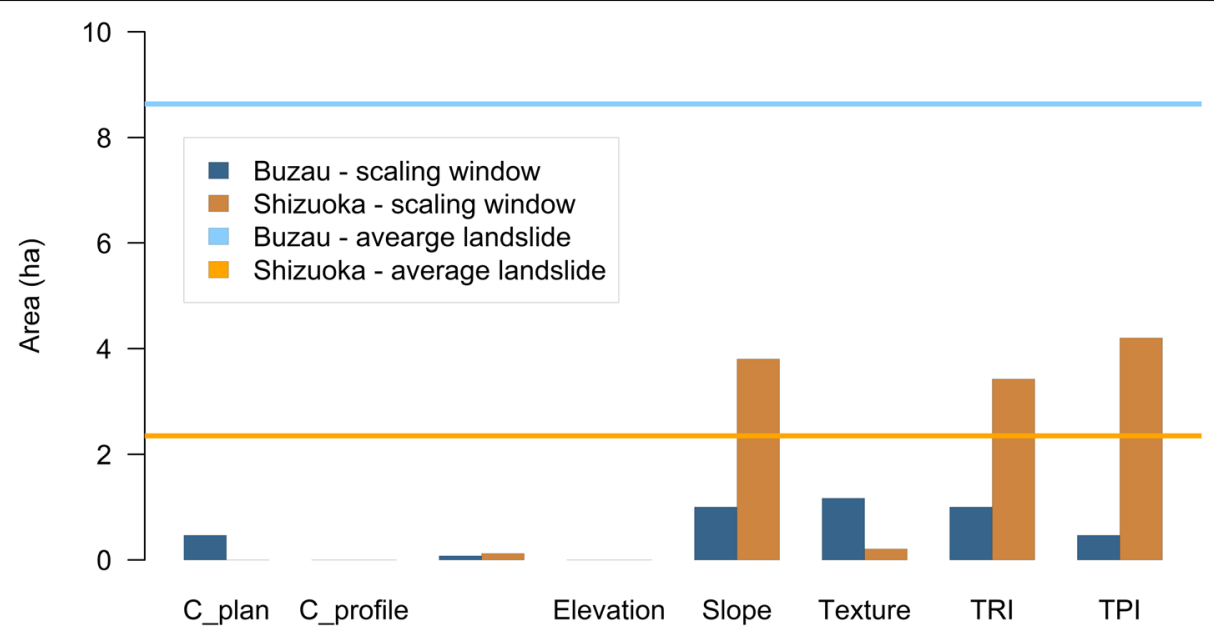

Fig. 9 A comparisons between the area that scaled variables represent (bars) and the average area of landslides (horizontal lines)

These results suggest that greater consideration should be given to the choice of DEMs, and their spatial resolution, when modeling landslides. Also, the fact that the lowest pixel size (i.e., highest spatial resolution) is not always the best option is highly important today with the increasing availability and use of DEMs with high to very high resolution.

The LSVs that are scaled broadly, to an area of more than $2500 \mathrm{~m}^{2}(50 \times 50 \mathrm{~m})$, seem to be less related with the microtopography developed on the landslides and more with the size of the landslides themselves. They are related to the findings of Claessens et al. (2005) who concluded that there is no universal DEM resolution for landslide modeling, and recommended that the DEM to be used should be adapted to the average size of the landslides.

For the Shizuoka study area, the three LSVs (slope, TRI, and TPI) that are scaled broadly represent an area greater than that of the average area of landslides whereas, the broadly scaled LSVs for the Buzau study area represent an area of approximately three times smaller than that of the average landslide. This can be related to the type and accuracy of the DEMs. The Lidar DEM used for the Shizuoka study area has a higher accuracy than that of the optically derived DEM for the
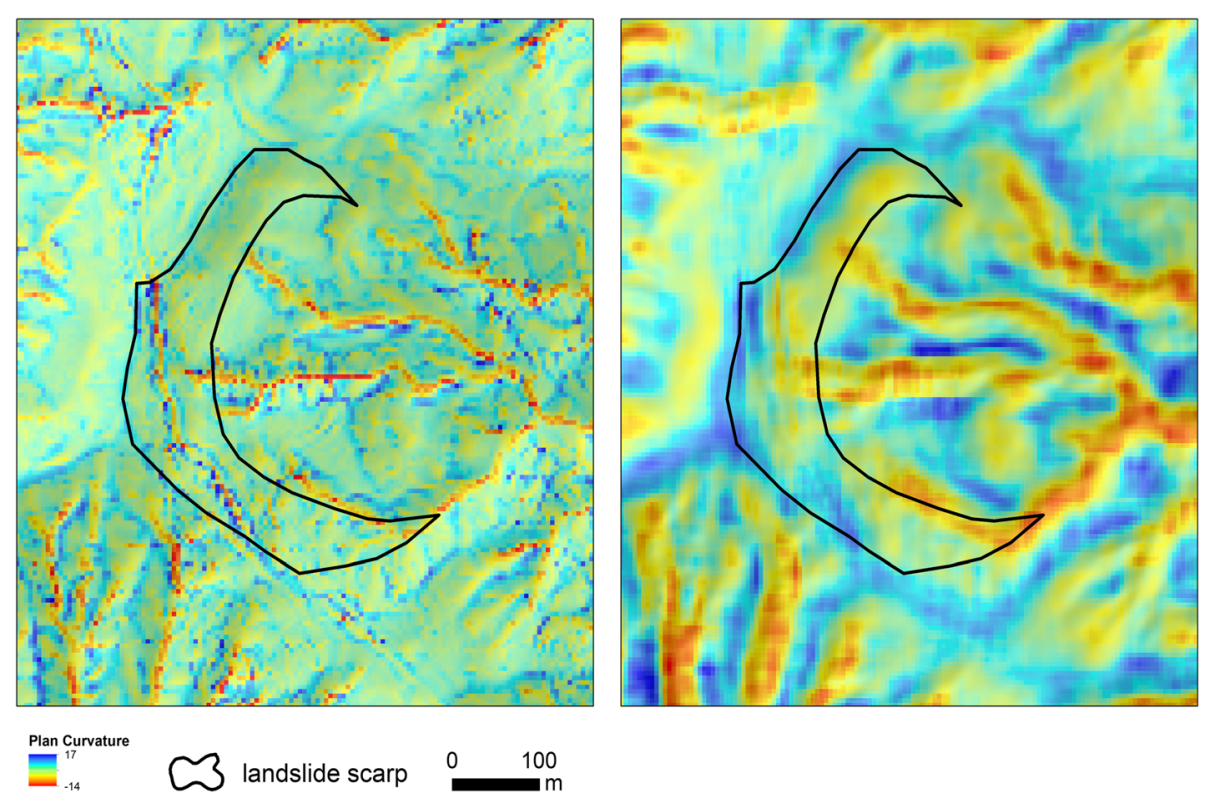

Fig. 10 Example of a scaled predictor in relation to a landslide scarp in the Shizuoka area. Left image: plan curvature at the default scale. Right image: plan curvature scaled in a $9 \times 9$ window. Note a north-south trench inside the landslide scarp on the left image is filtered out on the right image 
Buzau study area, and the latter has more artifacts resulted from the transformation from a DSM (digital surface model) to a DTM (digital terrain model). However, an even greater uncertainty in interpreting the relation between the area at which the LSVs were scaled and the area of the landslides is the variability in landslide size for the two study areas and that in size within each study area. This is valid especially in the Buzau area where the size differences between the more frequent smaller landslides and the bigger landslides are significant, and using only the average to express the size is statistically unrepresentative. The complex relation between the scaling factors of different predictors and the sizes of landslides under different conditions should be addressed in future studies.

\section{Scaling LSVs for landslide detection models vs landslide susceptibility models}

In recent years, more and more landslide inventories are created using automated or semi-automated models that can detect changes in the topography and/or land cover or that can be trained to identify the characteristics of landslides. The input for these models can be DEMs, remote sensing data or a combination of both.

The methodology that we propose here was developed and tested for detecting landslides in order to build a new inventory. We have chosen this approach, instead of a landslide susceptibility study because (i) it allows us to use landslides that are different in size and scarp characteristics, making the modeling more challenging and also reducing the risk of overfitting (creating an algorithm with good results on our data but with poor transferability), and (ii) it is easy to validate, since we already have the inventory of landslides that the algorithm predicts.

Different methods of scaling input data have been used for landslide susceptibility studies (Catani et al. 2013; Paudel et al. 2016). We estimate that our model for scaling can also be used in landslide susceptibility models. From the $\mathrm{R}$ script that is provided in Additional file 1, the scaling subroutine can be run independently of the rest of the script and can be used as a preprocessing step in a workflow of landslide susceptibility modeling. However, this should be tested in further studies.

\section{Conclusion}

We tested the hypothesis that scaling LSVs to better fit the observational scale improves modeling the presence/ absence of landslide scarps. The results show that when using scaled predictors, the models outperform the models with unscaled predictors. In terms of AUC values, an increase of 0.07 (0.73 to 0.80$)$ was achieved for the Shizuoka area and an increase of 0.14 (0.59 to 0.73) for the Buzau area. We further found that the importance of predictors in modeling changes as LSVs become more relevant at appropriate scales. These results highlight the importance of considering the scale of the input data in relation to the scaled of the modeled landslides. Therefore, we recommend that a multiscale analysis of the LSVs should be performed as a preprocessing of the input data before the modeling.

The proposed upscaling approach was integrated into a script available in Additional file 1, with a description and instructions to use in Additional file 2. The script can run automatically, as a preprocessing step in modeling, or it can run on a line by line base, in order to better analyze and understand the input data. This script can be applied to any DEM resolution in order to scaleup the input data to the size of geomorphological features.

In this paper, the errors that can be present in the two DEMs, and the other factors that can influence the modeling results, such as sampling strategy or modeling techniques are not discussed. Also, predictors that are known to have an important role in landslide modeling but are not derived from a DEM, like lithology and landcover, were not used. Those factors are beyond the scope of this paper and in order to test solely the influence of scaling the DEM-derived input variables, we had to keep all other factors constant, at the expense of potential loss in the overall accuracy of the model. Furthermore, we do not discuss the differences in the ranking of variable importance when computed with different methods. All of this should be addressed in future research.

\section{Additional files}

Additional file 1: $R$ scalling script. ( $7 \mathrm{~kb})$

Additional file 2: $\mathrm{R}$ script user guide. (DOCX $14 \mathrm{~kb}$ )

\section{Abbreviations}

ANCPI: Agentia Nationala de Cadastru si Publicitate Imobiliara (Romanian national agency for mapping and real estate); AUC: Area under the curve; DEM: Digital elevation model; DSM: Digital surface model; DTM: Digital terrain model; LSV: Land-surface variable; mtry: Number of candidate variables; ntree: Number of classification trees; OOB: Out of beg error; RF: Random forest; VI: Variable importance

\section{Acknowledgements}

This work was supported by a grant of Ministry of Research and Innovation, CNCS - UEFISCDI, project number PN-III-P4-ID-PCE-2016-0222, within PNCDI III.

\section{Authors' contributions}

FS performed the analyses, contributed to the research design, drafted the first version of the manuscript, and developed the script. LD contributed to the development of the idea, drafted the research design, and contributed to the final version of the manuscript. TO contributed to the development of the idea and to the final version of the manuscript. YH provided the data for the Japanese case study and contributed to the final version of the manuscript. MM provided the data for the Romanian case study and contributed to the final version of the manuscript. All authors read and approved the final manuscript. 


\section{Funding}

This work was supported by a grant of Ministry of Research and Innovation, CNCS-UEFISCDI, project number PN-III-P4-ID-PCE-2016-0222, within PNCDI III. The grant facilitated the acquisition of the DEM for the Romanian case study, payment of salaries for Flavius Sîrbu and Lucian Drăguț, fieldtrips and project meetings, conferences, and publication costs.

\section{Availability of data and materials}

The data for the Japanese case study (DEM and landslide inventory) are publicly available by the National Research Institute for Earth Science and Disaster Prevention (NIED), Japan. The DEM for the Romanian case study has been acquired under a license that forbids public release. The landslide inventory for the Romanian case study is the property of the Romanian Academy of Sciences; we do not have permission to make it publicly available. Preprocessing of these data can be performed by everyone with the tool available on the project's website: http://mapslide.projects.uvt.ro/ wp-content/uploads/2017/12/Scalling-Tool.7z

\section{Competing interests}

The authors declare that they have no competing interests.

\section{Author details}

${ }^{1}$ Department of Geography, West University of Timisoara, Bd. V. Parvan 4, 300223 Timisoara, Romania. ${ }^{2}$ Center for Spatial Information Science, The University of Tokyo, 5-1-5 Kashiwanoha, Kashiwa-shi, Chiba 277-8568, Japan. ${ }^{3}$ Institute of Geography, Romanian Academy, 023993 Bucharest, Romania.

${ }^{4}$ Faculty of Environmental Earth Science, Hokkaido University, N10W5 Kita-ku, Sapporo, Hokkaido 060-0810, Japan.

\section{Received: 17 December 2018 Accepted: 27 May 2019}

Published online: 13 June 2019

\section{References}

Arnone E, Francipane A, Scarbaci A, Puglisi C, Noto LV (2016) Effect of raster resolution and polygon-conversion algorithm on landslide susceptibility mapping. Environ Model Softw 84:467-481. https://doi.org/10.1016/j.envsoft. 2016.07.016

Becker D, de Andres-Herrero M, Willmes C, Weniger GC, Bareth G (2017) Investigating the influence of different DEMs on GIS-based cost distance modeling for site catchment analysis of prehistoric sites in Andalusia. ISPRS Int Geo-Inf 6:28. https://doi.org/10.3390/ijgi6020036

Behnia P, Blais-Stevens A (2018) Landslide susceptibility modelling using the quantitative random forest method along the northern portion of the Yukon Alaska highway corridor, Canada. Nat Hazards 90:1407-1426. https://doi.org/ 10.1007/s11069-017-3104-z

Bishop MP, James LA, Shroder JF, Walsh SJ (2012) Geospatial technologies and digital geomorphological mapping: concepts, issues and research. Geomorphology 137:5-26. https://doi.org/10.1016/j.geomorph.2011.06.027

Breiman L (2001) Random forests. Mach Learn 45:5-32. https://doi.org/10.1023/a: 1010933404324

Brenning A (2005) Spatial prediction models for landslide hazards: review, comparison and evaluation. Nat Hazards Earth Syst Sci 5:853-862. https://doi. org/10.5194/nhess-5-853-2005

Brenning A (2008) Statistical geocomputing combining R and SAGA: the example of landslide susceptibility analysis with generalized additive models. In: Boehner J, Blaschke T, Montanarella L (eds) SAGA--Seconds Out, vol 19. Hamburger Beitraege zur Physischen Geographie und Landschaftsoekologie, Hamburg, pp 23-32

Broeckx J, Vanmaercke M, Balteanu D, Chendes V, Sima M, Enciu P, Poesen J (2016) Linking landslide susceptibility to sediment yield at regional scale: application to Romania. Geomorphology 268:222-232. https://doi.org/10. 1016/j.geomorph.2016.06.012

Cantreul V, Bielders C, Calsamiglia A, Degre A (2018) How pixel size affects a sediment connectivity index in Central Belgium. Earth Surf Process Landf 43: 884-893. https://doi.org/10.1002/esp.4295

Catani F, Lagomarsino D, Segoni S, Tofani V (2013) Landslide susceptibility estimation by random forests technique: sensitivity and scaling issues. Nat Hazards Earth Syst Sci 13:2815-2831. https://doi.org/10.5194/nhess-13-28152013

Cauzzi C, Fah D, Wald DJ, Clinton J, Losey S, Wiemer S (2018) ShakeMap-based prediction of earthquake-induced mass movements in Switzerland calibrated on historical observations. Nat Hazards 92:1211-1235. https://doi.org/10. 1007/s11069-018-3248-5

Chen F, Yu B, Li B (2018) A practical trial of landslide detection from singletemporal Landsat8 images using contour-based proposals and random forest: a case study of national Nepal. Landslides 15:453-464. https://doi.org/ 10.1007/s10346-017-0884-x

Chen W, Xie XS, Wang JL, Pradhan B, Hong HY, Bui DT, Duan Z, Ma JQ (2017) A comparative study of logistic model tree, random forest, and classification and regression tree models for spatial prediction of landslide susceptibility. Catena 151:147-160. https://doi.org/10.1016/j.catena.2016.11.032

Claessens L, Heuvelink GBM, Schoorl JM, Veldkamp A (2005) DEM resolution effects on shallow landslide hazard and soil redistribution modelling. Earth Surf Process Landf 30:461-477. https://doi.org/10.1002/esp.1155

Conrad O et al (2015) System for automated geoscientific analyses (SAGA). v. 2.1. 4. Geosci Model Dev 8:1991-2007. https://doi.org/10.5194/gmd-8-1991-2015

Damen M, Micu M, Zumpano V, Van Westen CJ, Sijmons K, Balteanu D (2014) Landslide mapping and interpretation: implications for landslide susceptibility analysis in discontinuous data environment. Conference Analysis and Management of Changing Risks for Natural Hazards, pp 177186, 705

Dekavalla M, Argialas D (2017) Evaluation of a spatially adaptive approach for land surface classification from digital elevation models. Int J Geogr Inf Sci 31:1978-2000. https://doi.org/10.1080/13658816.2017.1344984

Deluigi N, Lambiel C, Kanevski M (2017) Data-driven mapping of the potential mountain permafrost distribution. Sci Total Environ 590:370-380. https://doi. org/10.1016/j.scitotenv.2017.02.041

Dragut L, Schauppenlehner T, Muhar A, Strobl J, Blaschke T (2009) Optimization of scale and parametrization for terrain segmentation: an application to soillandscape modeling. Comput Geosci 35:1875-1883. https://doi.org/10.1016/j. cageo.2008.10.008

Gariano SL, Rianna G, Petrucci O, Guzzetti F (2017) Assessing future changes in the occurrence of rainfall-induced landslides at a regional scale. Sci Total Environ 596:417-426. https://doi.org/10.1016/j.scitotenv.2017.03.103

Garosi Y, Sheklabadi M, Pourghasemi HR, Besalatpour AA, Conoscenti C, Van Oost $\mathrm{K}$ (2018) Comparison of differences in resolution and sources of controlling factors for gully erosion susceptibility mapping. Geoderma 330:65-78. https://doi.org/10.1016/j.geoderma.2018.05.027

Goetz JN, Brenning A, Petschko H, Leopold P (2015) Evaluating machine learning and statistical prediction techniques for landslide susceptibility modeling. Comput Geosci 81:1-11. https://doi.org/10.1016/j.cageo.2015.04.007

Goetz JN, Guthrie RH, Brenning A (2011) Integrating physical and empirical landslide susceptibility models using generalized additive models. Geomorphology 129 : 376-386. https://doi.org/10.1016/j.geomorph.2011.03.001

Goodchild MF (2001) Metrics of scale in remote sensing and GIS. Int J Appl Earth Obs Geoinf 3:114-120. https://doi.org/10.1016/S0303-2434(01)85002-9

Guzzetti F, Mondini AC, Cardinali M, Fiorucci F, Santangelo M, Chang KT (2012) Landslide inventory maps: new tools for an old problem. Earth-Sci Rev 112(1-2):42-66

Hosmer DW, Lemeshow S (2000) Applied Logistic Regression. Wiley, New York. https://doi.org/10.1002/0471722146

Iverson RM, George DL, Allstadt K, Reid ME, Collins BD, Vallance JW, Schilling SP, Godt JW, Cannon CM, Magirl CS, Baum RL, Coe JA, Schulz WH, Bower JB (2015) Landslide mobility and hazards: implications of the 2014 Oso disaster. Earth Planet Sci Lett 412:197-208

Iwahashi J, Pike RJ (2007) Automated classifications of topography from DEMs by an unsupervised nested-means algorithm and a three-part geometric signature. Geomorphology 86:409-440. https://doi.org/10.1016/j.geomorph. 2006.09.012

Lagomarsino D, Tofani V, Segoni S, Catani F, Casagli N (2017) A tool for classification and regression using random forest methodology: applications to landslide susceptibility mapping and soil thickness modeling. Environ Model Assess 22:201-214. https://doi.org/10.1007/s10666-016-9538-y

Li J, Wong DWS (2010) Effects of DEM sources on hydrologic applications. Comput Environ Urban Syst 34:251-261. https://doi.org/10.1016/j. compenvurbsys.2009.11.002

Liaw A, Wiener M (2002) Classification and regression by random forest. R News 2:18-22 doi:citeulike-article-id:1121494

Liffner JW, Hewa GA, Peel MC (2018) The sensitivity of catchment hypsometry and hypsometric properties to DEM resolution and polynomial order. Geomorphology 309:112-120. https://doi.org/10.1016/j. geomorph.2018.02.022 
Lombardo L, Opitz T, Huser R (2018) Point process-based modeling of multiple debris flow landslides using INLA: an application to the 2009 Messina disaster. Stoch Environ Res Risk Assess 32:2179-2198. https://doi.org/10.1007/ s00477-018-1518-0

Lu X, Li Y, Washington-Allen RA, Li Y, Li H, Hu Q (2017) The effect of grid size on the quantification of erosion, deposition, and rill network. Int Soil Water Conserv Res 5:241-251. https://doi.org/10.1016/j.iswcr.2017.06.002

Moore ID, Grayson RB, Ladson AR (1991) Digital terrain modeling-a review of hydrological, geomorphological and biological applications. Hydrol Process 5: 3-30. https://doi.org/10.1002/hyp.3360050103

Olaya V (2004) A gentle introduction to SAGA GIS. Available from: http:// downloads.sourceforge.net/saga-gis/SagaManual.pdf. Accessed 4 June 2019

Oyagi N, Uchiyama S, Ogura M (2015) Explanations of landslide distribution maps. Technical note of the National Research Institute for Earth Science and Disaster Resilience, vol 394, pp 391-314

Paudel U, Oguchi T, Hayakawa Y (2016) Multi-resolution landslide susceptibility analysis using a DEM and random Forest. Int J Geosci 07(05):18. https://doi. org/10.4236/ijg.2016.75056

Pawluszek K, Borkowski A, Tarolli P (2018) Sensitivity analysis of automatic landslide mapping: numerical experiments towards the best solution. Landslides 15(9):1851-1865

Peppa MV, Mills JP, Moore P, Miller PE, Chambers JE (2019) Automated coregistration and calibration in SFM photogrammetry for landslide change detection. Earth Surf Process Landf 44(1):287-303

Pike RJ, Evans IS, Hengl T (2008) Geomorphometry: a brief guide. In: Hengl T, Reuter HI (eds) Geomorphometry: concepts, software, applications, vol 33 Elsevier, Amsterdam, p 772

R_Core_Team (2017) R: a language and environment for statistical computing. R Foundation for statistical computing, Vienna

Reichenbach P, Rossi M, Malamud BD, Mihir M, Guzzetti F (2018) A review of statistically-based landslide susceptibility models. Earth-Sci Rev 180:60-91. https://doi.org/10.1016/j.earscirev.2018.03.001

Santacana N, Baeza B, Corominas J, De Paz A, Marturia J (2003) A GIS-based multivariate statistical analysis for shallow landslide susceptibility mapping in La Pobla de Lillet area (Eastern Pyrenees, Spain). Nat Hazards 30:281-295. https://doi.org/10.1023/b:nhaz.0000007169.28860.80

Scaioni M, Longoni L, Melillo V, Papini M (2014) Remote sensing for landslide investigations: an overview of recent achievements and perspectives. Remote Sens 6(10):9600-9652

Schlögel R, Marchesini I, Alvioli M, Reichenbach P, Rossi M, Malet JP (2018) Optimizing landslide susceptibility zonation: effects of DEM spatial resolution and slope unit delineation on logistic regression models. Geomorphology 301:10-20. https://doi.org/10.1016/j.geomorph.2017.10.018

Schmidt J, Andrew R (2005) Multi-scale landform characterization. Area 37:341350. https://doi.org/10.1111/j.1475-4762.2005.00638.x

Segoni S, Rosi A, Lagomarsino D, Fanti R, Casagli N (2018) Brief communication: using averaged soil moisture estimates to improve the performances of a regional-scale landslide early warning system. Nat Hazards Earth Syst Sci 18 : 807-812. https://doi.org/10.5194/nhess-18-807-2018

Shimizu F, Yagi K, Inokuchi T, Oyagi N (2002) Landslide maps series 14 "Shizuoka". Technical Note of the National Research Institute for Earth Science and Disaster Resilience, p 221

Sing T, Sander O, Beerenwinkel N, Lengauer T (2005) ROCR: visualizing the performance of scoring classifiers. Bioinformatics 21:7881

Sulaiman WNA, Rosli MH, Abu Samah MA, Kamarudin MKA (2017) Landslide susceptibility mapping: effect of spatial resolution towards the prediction of landslide prone area in a tropical catchment. Chiang Mai J Sci 44:494-507

Uchiyama S, Doshida S, Oyagi N, Shimizu F (2012) The NIED landslide mapping team

Wang J, Jin W, Y-f C, W-f Z, Wu C-h, Alessandro P (2018) Earthquake-triggered landslides affecting a UNESCO natural site: the 2017 Jiuzhaigou earthquake in the World National Park, China. J Mt Sci 15:1412-1428. https://doi.org/10. 1007/s11629-018-4823-7

Wang T, Liu JM, Shi JS, Wu SR (2017) The influence of DEM resolution on seismic landslide hazard assessment based upon the Newmark displacement method: a case study in the loess area of Tianshui. China Environ Earth Sci 76:10. https://doi.org/10.1007/s12665-017-6944-7

Youssef AM, Pourghasemi HR, Pourtaghi ZS, Al-Katheeri MM (2016) Landslide susceptibility mapping using random forest, boosted regression tree, classification and regression tree, and general linear models and comparison of their performance at Wadi Tayyah Basin, Asir region,
Saudi Arabia. Landslides 13:839-856. https://doi.org/10.1007/s10346-0150614-1

Zhang WH, Montgomery DR (1994) Digital elevation model grid size, landscape representation and hydrologic simulations. Water Resour Res 30:1019-1028. https://doi.org/10.1029/93wr03553

Zhilin L (2008) Multi-scale digital terrain modelling and analysis. In: Zhou Q, Lees B, Tang G (eds) Advances in digital terrain analysis. Springer, Berlin, pp 59-83. https://doi.org/10.1007/978-3-540-77800-4_4

Zumpano V (2014) Development of a method for constructing risk scenario and risk maps with associated uncertainties. PhD thesis, Manuscript. Institute of Geography, Bucharest

Zumpano V, Hussin H, Reichenbach P, Bãlteanu D, Micu M, Sterlacchini S (2014) A landslide susceptibility analysis for Buzãu County, Romania. Revue Roumaine de Geographie/Rom J Geogr 58(1):9-16

\section{Publisher's Note}

Springer Nature remains neutral with regard to jurisdictional claims in published maps and institutional affiliations.

\section{Submit your manuscript to a SpringerOpen ${ }^{\circ}$ journal and benefit from:}

- Convenient online submission

- Rigorous peer review

- Open access: articles freely available online

High visibility within the field

- Retaining the copyright to your article

Submit your next manuscript at $\boldsymbol{\nabla}$ springeropen.com 